\title{
Stereoselective effects of statins on xenobiotic-metabolizing pathways
}

Martina Korhonova and Zdenek Dvorak Email: m.korhonova@gmail.com

Department of Cell Biology and Genetics, Faculty of Science, Palacky University, Slechtitelu 27, 78371 Olomouc, Czech Republic

\section{Introduction:}

Several of currently used drugs are chiral compounds. Majority of them are clinically administered as a racemic (equimolar) mixture of enantiomers. Individual enantiomers of one drug can qualitatively and quantitatively differ in their biological activities (pharmacology, toxicology, pharmacokinetics, etc.). Therefore, enantiopure drugs have been developed and introduced to the therapy.

Statins are drugs used to lower cholesterol levels by inhibiting the enzyme HMG-CoA reductase. Atorvastatin, rosuvastatin and fluvastatin are the most often prescribed statins. They have two chiral centres, thus they form four enantiomers: 3R5R-, 3R5S-, 3S5R- and 3S5S- (Figure 1). They are marketed as a racemic mixture of these enantiomers; however their enantiopure forms have been introduced to clinic recently (3R5R-atorvastatin, 3R5S rosuvastatin and 3R5S-fluvastatin).

In this study, we investigated enantiospecific interactions of all four enantiopure forms of atorvastin, rosuvastatin and fluvastatin with main transcriptional regulators of drugmetabolizing enzymes - aryl hydrocarbon receptor (AhR), glucocorticoid receptor (GR) and pregnane $X$ receptor (PXR). Agonist and antagonist activities of tested compounds towards $A h R, P X R$ and $G R$ were determined using human reporter cell lines.
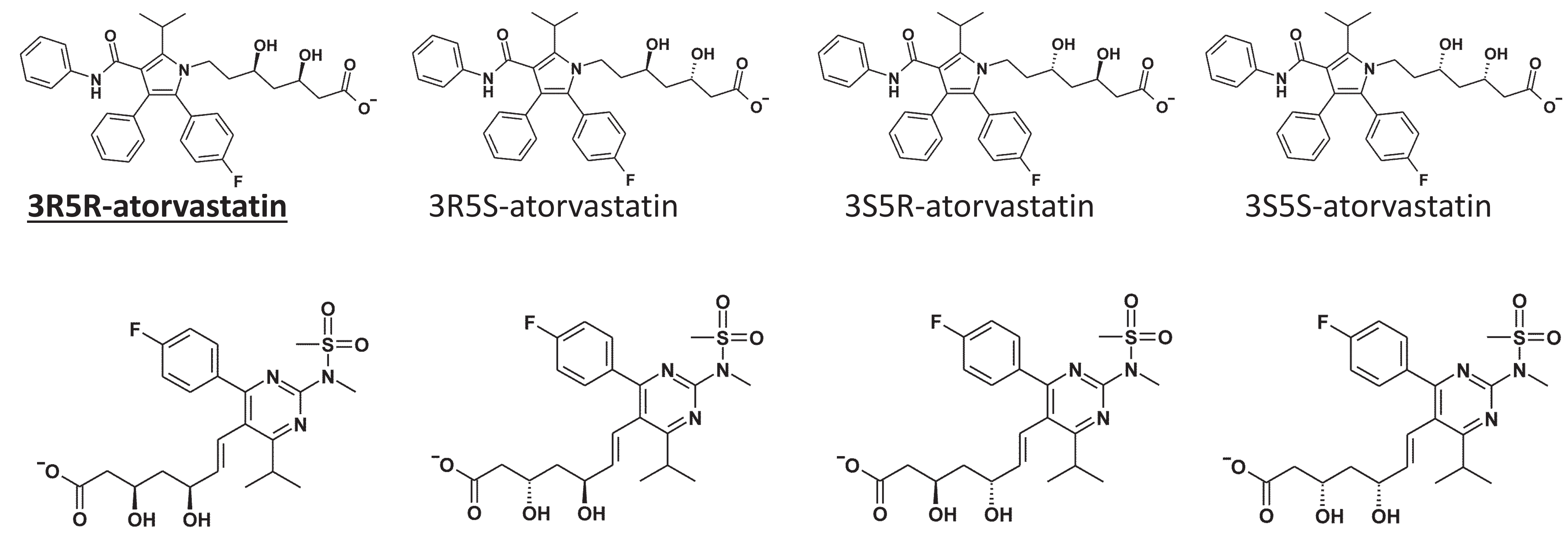

3R5R-rosuvastatin
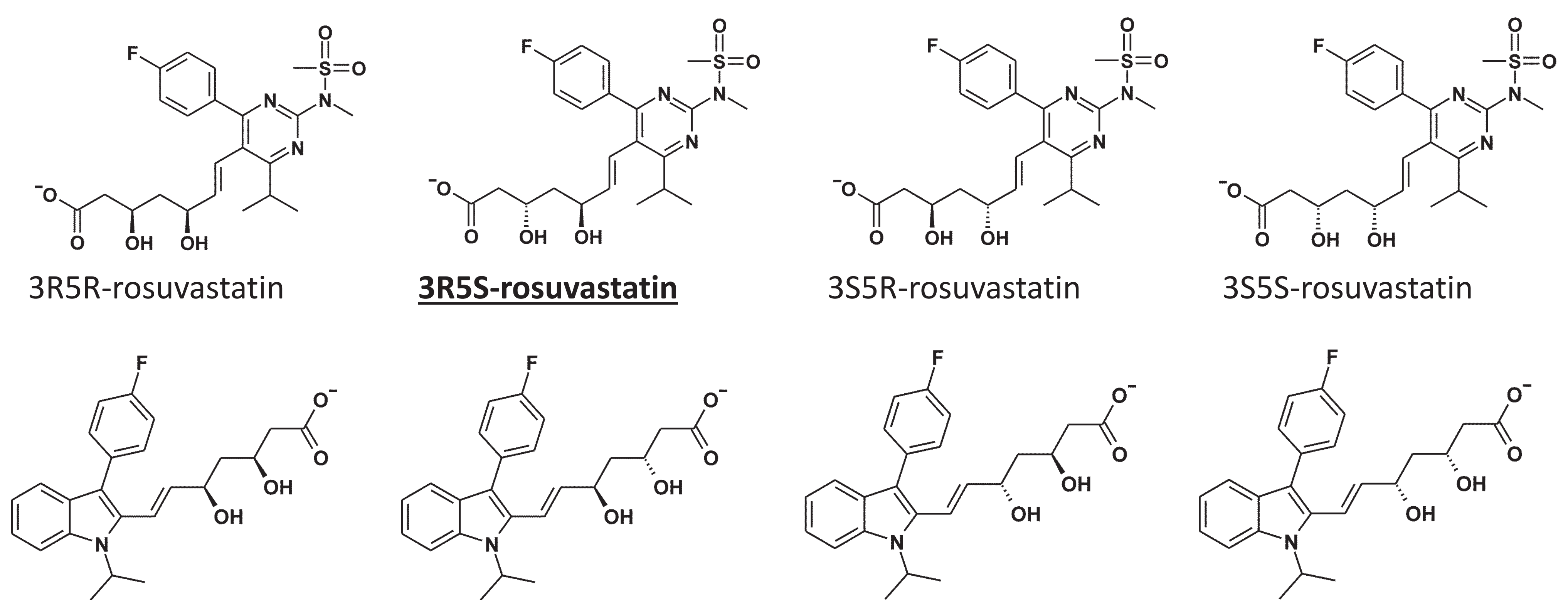

3S5S-rosuvastatin
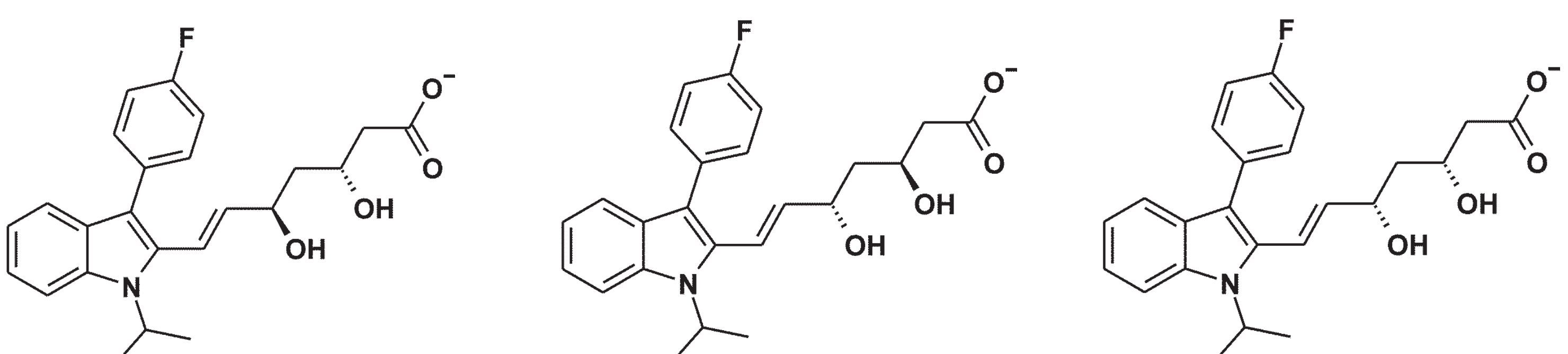

3R5R-fluvastatin

3R5S-fluvastatin

3S5R-fluvastatin

3S5S-fluvastatin

\section{Gene reporter assay and cytotoxicity assay:}

A stably transfected gene reporter cell line AZ-AHR and AZ-GR established in our laboratory were used for assessment of AhR and GR transcriptional activity. Transiently transfected LS180 human colon adenocarcinoma cells were used for assessment of PXR transcriptional activity. A chimera p3A4-luc reporter construct containing the basal promoter $(-362 /+53)$ with proximal PXR response element and the distal xenobiotic responsive enhancer module $(-7836 /-7208)$ of the CYP3A4 gene 50-flanking region inserted to pGL3-Basic reporter vector was used. The reporter plasmid was transiently transfected to LS180 cells by lipofection (FuGENE ${ }^{\circledR}$ HD Transfection Reagent).

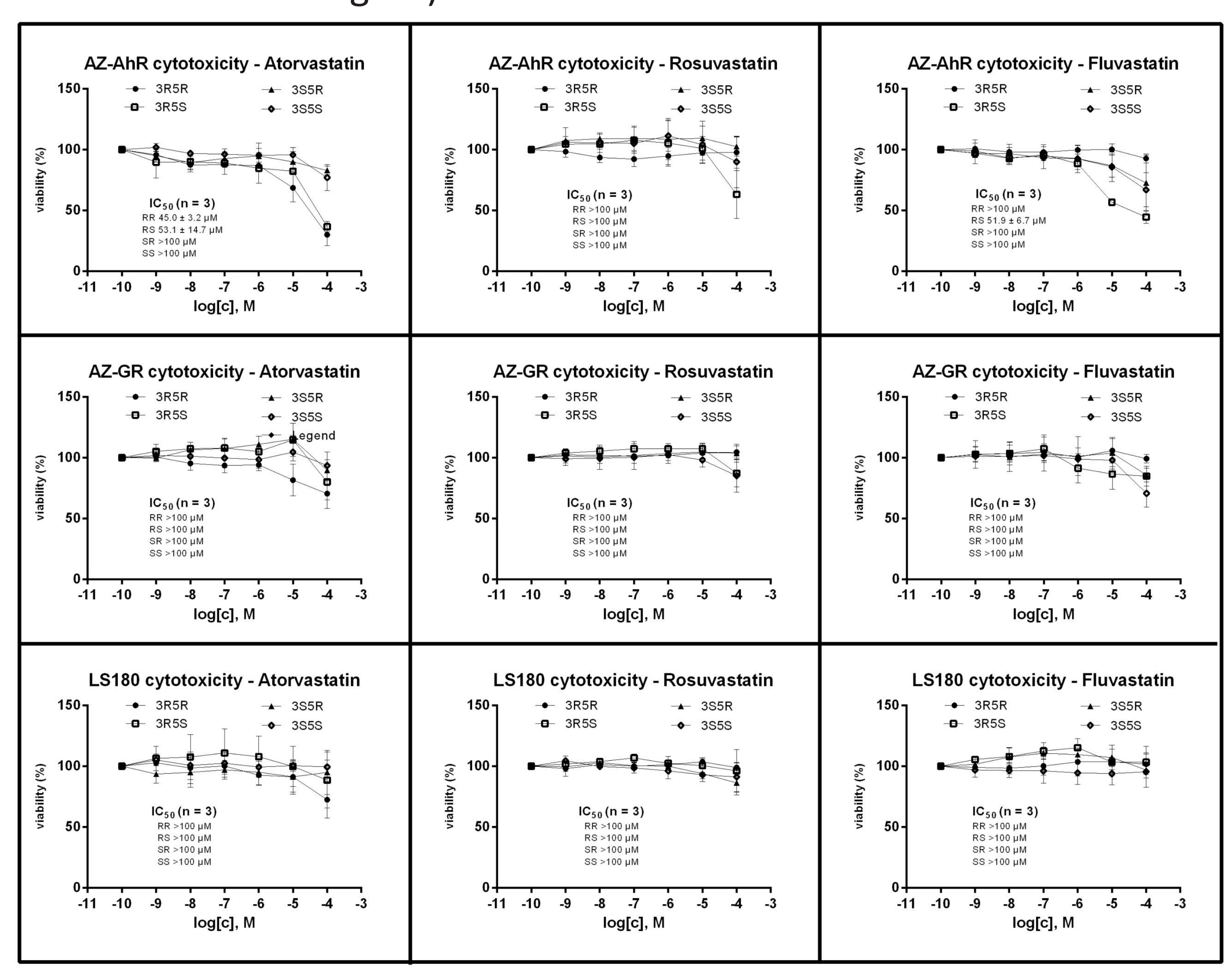

Fig. 2: Cytotoxicity of statin enantiomers in human cancer cell lines.

Prior to gene reporter assays, we examined the cytotoxicity of tested compounds in AZ-AHR, AZ-GR and LS180 cell lines. For this purpose, the cells were incubated for $24 \mathrm{~h}$ with individual enantiomers of atorvastatin, fluvastatin and rosuvastatin at concentrations ranging from $100 \mathrm{pM}$ to $100 \mu \mathrm{M}$. The vehicle was DMSO (0.1\% v/v). After the treatment, conventional MTT test was performed and absorbance was measured at $540 \mathrm{~nm}$ (Figure 2) The data are the mean \pm SD from experiments performed in three consecutive passages of cells and are expressed as percentage of viability of control cells. The values of IC50 wer calculated where appropriate and they are indicated in plots. Based on the results from cytotoxicity testing (Figure 2), gene reporter assays were performed in concentrations of tested compounds up to $100 \mu \mathrm{M}$, with exception of atorvastatin, where maximal concentration of $10 \mu \mathrm{M}$ was used for incubations in AZ-AHR and AZ-GR cells.

\section{References:}

Novotna, A. et al., Environmental science \& technology 2011, 45, 10133-10139.

Novotna, A. et al.,European Journal of Pharmaceutical Sciences 2012, 47, 842-847.

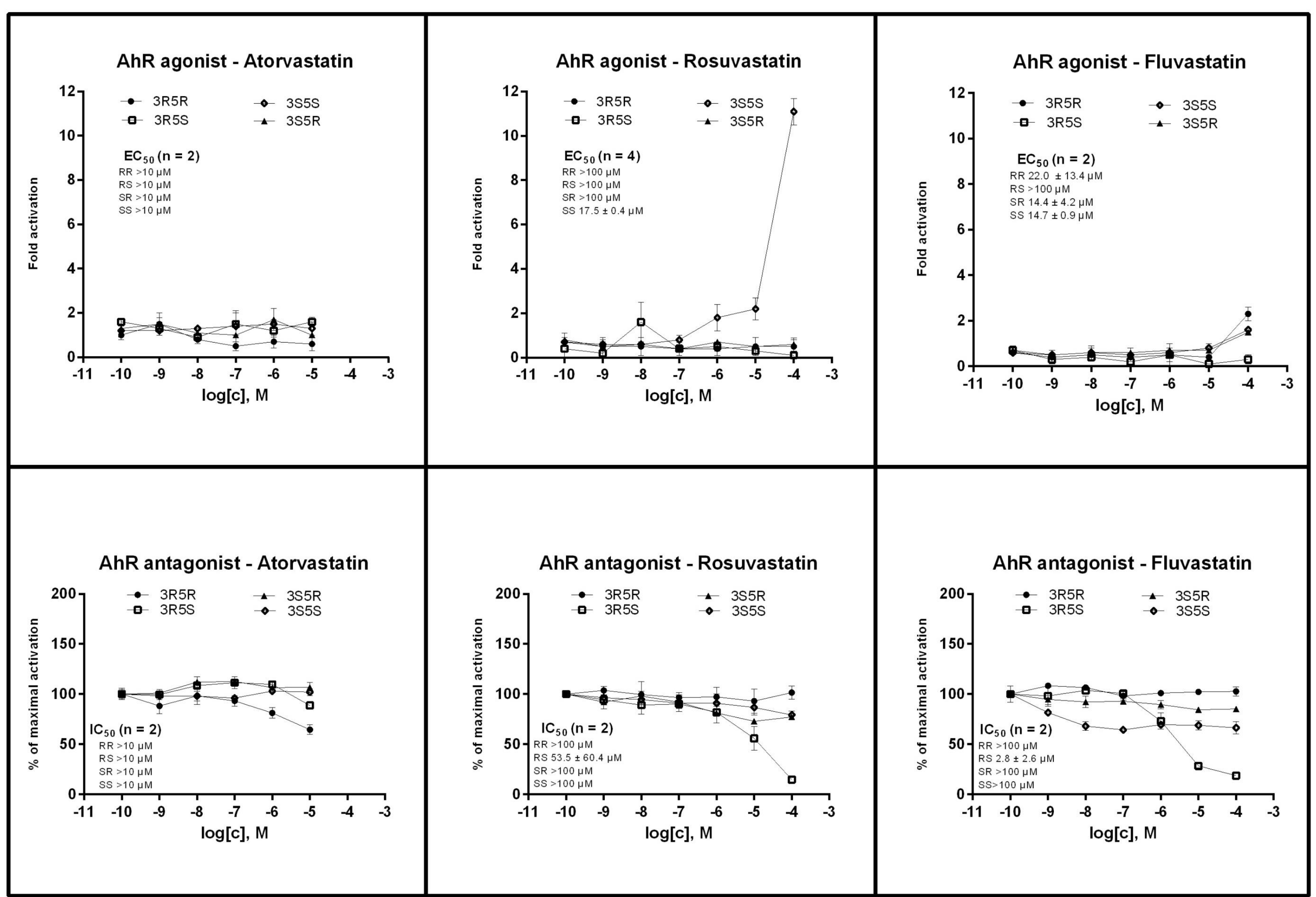

Fig. 3: Effects of statin enantiomers on transcriptional activity of aryl hydrocarbon receptor. Transcriptional activity of AhR was assessed in human gene reporter cell line AZ-AHR incubated for $24 \mathrm{~h}$ with tested compounds in the presence (antagonist mode) or absence (agonist mode) of model agonist 2,3,7,8-tetrachlorodibenzo-p-dioxin (TCDD; 5 nM). 3S5Srosuvastatin dose-dependently increased luciferase activity $(0.1 \%$ of induction by TCDD). 3R5R-, 3S5R- and 3S5S-fluvastatin slightly increased luciferase activity $(0.01 \%$ of induction by TCDD). TCDD-inducible transcriptional activity of AhR was dose-dependently inhibited by 3R5S-rosuvastatin and 3R5S-fluvastatin (Figure 3). The decrease of TCDD-inducible luciferase activity correlated with decrease of AZ-AHR cells viability.

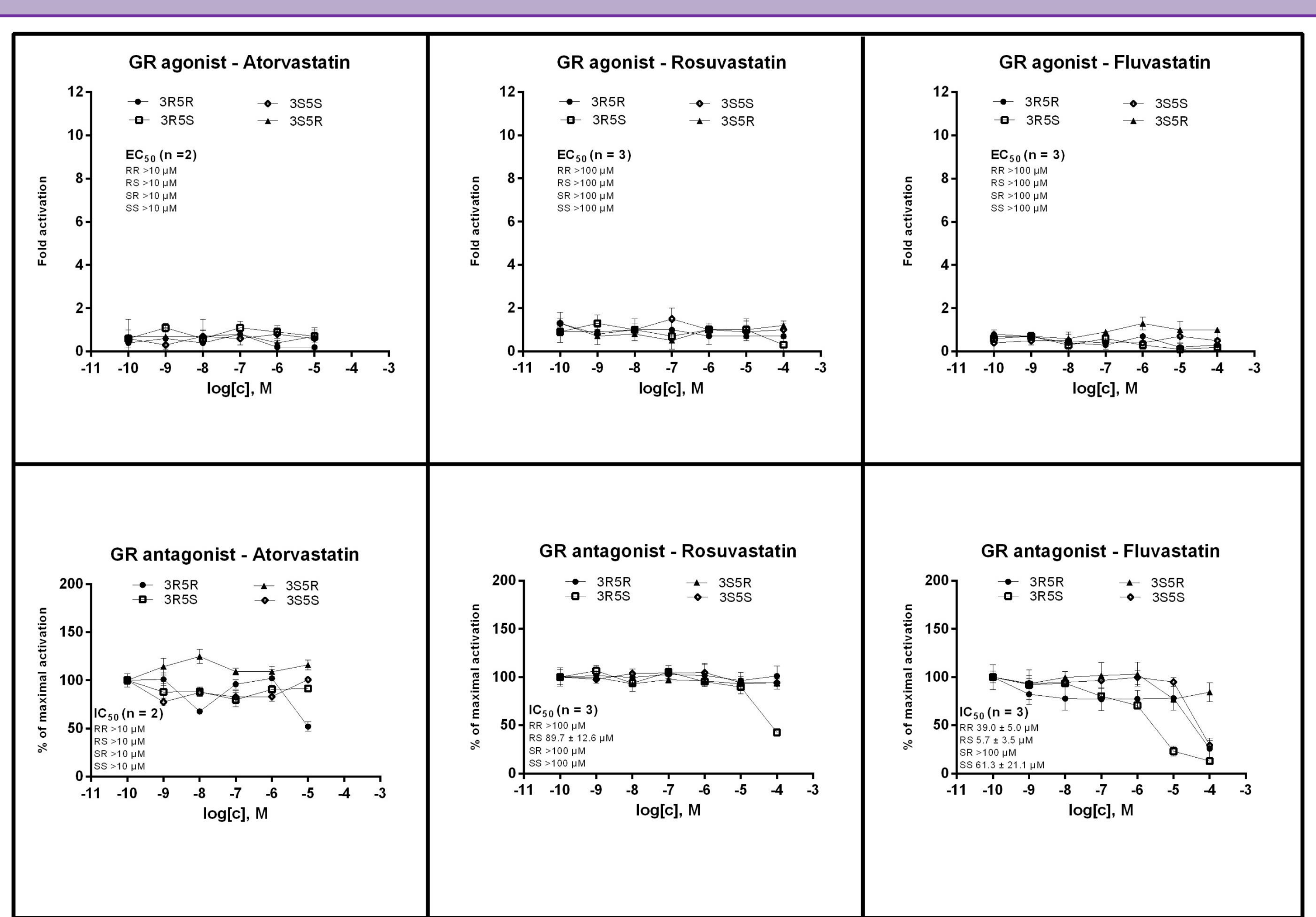

Fig. 4: Effects of statin enantiomers on transcriptional activity of glucocorticoid receptor Transcriptional activity of GR was assessed in human gene reporter cell line AZ-GR incubated for $24 \mathrm{~h}$ with tested compounds. Dexamethasone (100 $\mathrm{nM}$ ) was used as a model agonist. None of the tested statins induced GR-dependent luciferase activity. Dexamethasone-inducible transcriptional activity of GR was decreased by antagonized by 3R5R-atorvastatin $(10 \mathrm{mM})$ and 3R5S-rosuvastatin $(100 \mathrm{mM})$, but the decrease occurred probably due to the cytotoxicity of tested compounds. 3S5S-, 3R5R- and 3R5S-fluvastatin dose-dependently antagonized GR and there were significant differences between fluvastatin optical isomers (Figure 4).

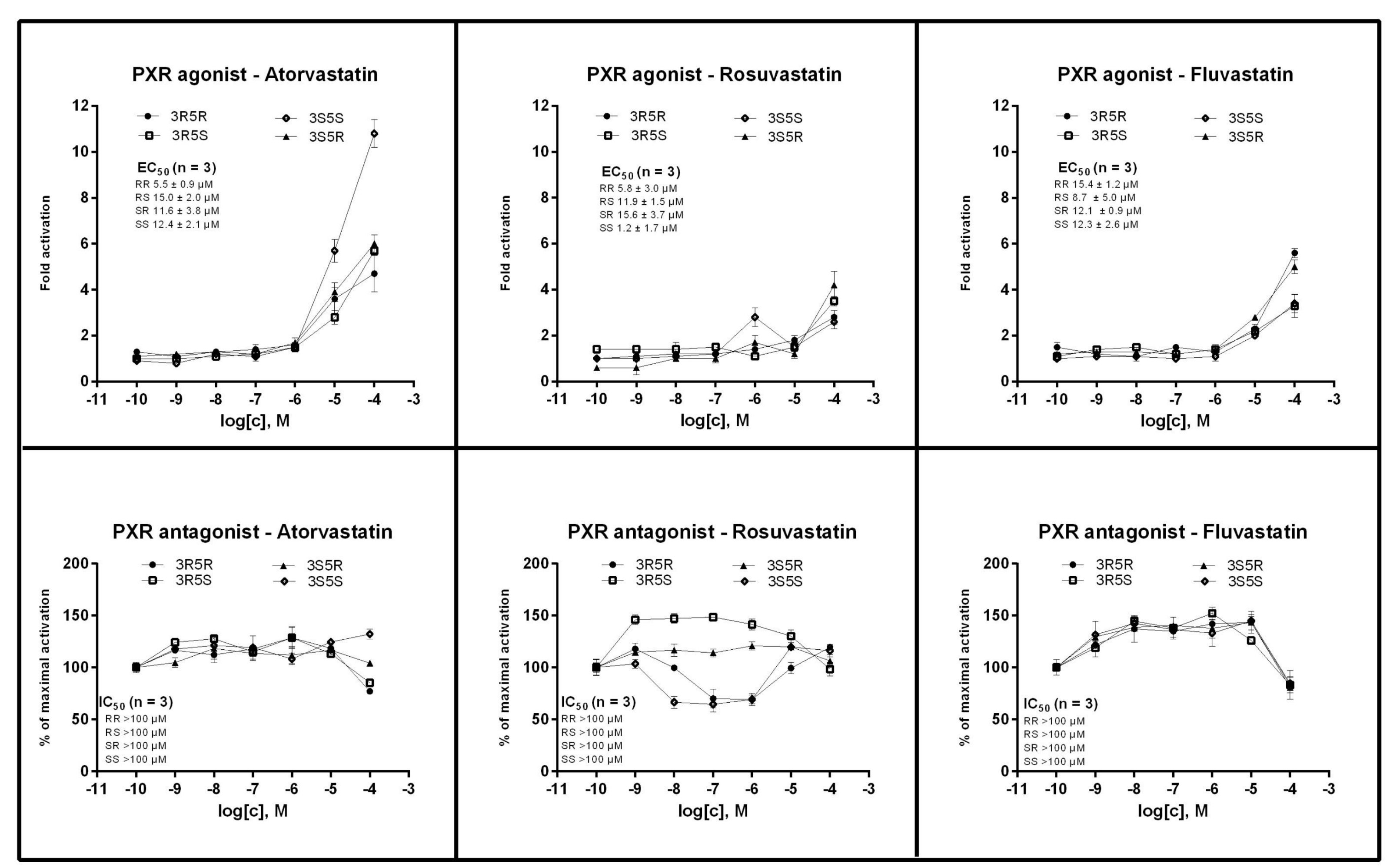

Fig. 5: Effects of statin enantiomers on transcriptional activity of pregnane $\mathrm{X}$ receptor. Transcriptional activity of PXR was tested in human colon adenocarcinoma cells LS180 transiently transfected with p3A4-luc reporter construct, incubated for $24 \mathrm{~h}$ with tested compounds. Rifampicin $(10 \mu \mathrm{M})$ was used as a model agonist. Transcriptional activity of PXR was dose-dependently induced by all tested statins, and the potency and efficacy between individual optical isomers varied substantially. Rifampicin-inducible transcriptional activity of PXR was influenced by all tested statins, again differentially, depending on statin and optical isomer (Figure 5).

Conclusion: We have demonstrated significantly different stereospecific effects of tested statins on transcriptional activity of glucocorticoid and pregane $\mathrm{X}$ receptor. Recently, we study the enantiospecific effects of statin enantiomers on the expression of drug metabolizing enzymes CYPs on mRNA and protein level in primary human hepatocytes.

Financial support from Czech Scientific agency 13-01809S and Students project of Palacky University Olomouc PrF-2015-003 is greatly acknowledged. 